\title{
SEISMICITY CRITERIA FOR THE REAL-TIME IDENTIFICATION OF FORESHOCKS IN THE CORINTH GULF
}

Orfanogiannaki K. and Papadopoulos G.A.

Institute of Geodynamics, National Observatory of Athens, 11810 Athens,

kOrfanogiannaki@freemail.gr,g.papad@gein.noa.gr

\section{ABSTRACT}

In the Corinth Gulf foreshock sequences occur as a rule within a time interval no longer than four months before the mainshock. If these precursory phenomena could be detected, then it would be utilized for the prediction of the mainshock. However, frequent swarms also characterize the Gulf of Corinth. Therefore, in a real time evaluation, the discrimination between swarms and foreshock sequences is of crucial importance. In this study we focus on establishing seismicity criteria to achieve such discrimination.

\section{INTRODUCTION}

Foreshocks have long been studied as one of the most promising earthquake precursors since they possess some distinct properties. In fact, they occur a few hours, days or weeks before the mainshock, while their number increases with time following the power-law distribution:

$$
n=n_{0} \cdot t^{-p}
$$

where $n$ is the number of foreshocks at time $t$ and $n_{0}, p$ are parameters. In addition, the value of the parameter $b$ of the magnitude-frequency relationship is smaller in foreshocks than in background seismic activity (Agnew \& Jones 1991, Chen et al. 1999, Jones 1984, 1985, Jones \& Molnar 1979, Ishida \& Kanamori 1978, Kagan \& Knopoff 1978, Michael \& Jones 1998, Molchan \& Dmitrieva 1990, Ogata et al. 1996, Papazachos 1973, 1975, Reasenberg 1999, Suyehiro \& Sekiya 1972). Foreshocks have been particularly studied in Greece in about the last thirty years or so (Papazachos 1973, 1975, Wong \& Wyss 1985, Papadopoulos et al. 1991, 2000). Foreshock activity occurs frequently in the Corinth Gulf in a time interval of no longer than about four months before strong mainshocks, while, the probability of occurrence of the largest foreshock within the last ten days before the mainshock is greater than $83 \%$ (Papadopoulos et al. 2000). For these reasons the Corinth Gulf (Fig.1) has been selected as a seismotectonic unit suitable for the foreshock detection before mainshocks.

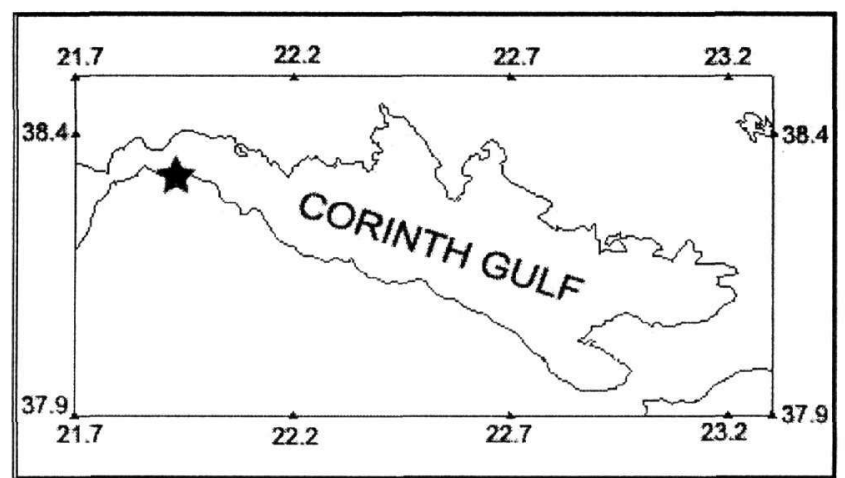

Figure 1. The area of Corinth Gulf. The star shows the epicenter of the example event of Fig. 2 . 
Moreover, it is a segment of seismotectonic homogeneity, with a N-S tensional stress field and major normal faults striking nearly E-W, as well as of high seismicity providing a large amount of observational material. Figure 2 shows an example of a foreshock sequence appearing about three months before the mainshock.

\section{THE PROBLEM}

A major problem involved in the procedure of identifying the onset of a particular foreshock sequence in real-time, is that one should exclude, with high degree of confidence, the possibility that the earthquake sequence does not constitute a swarm-type activity that does not lead to the generation of a mainshock. Therefore, there is need to define the properties of swarm activities in the Corinth Gulf, to compare them with the properties of the foreshock sequences and then to establish a procedure for the discrimination between swarms and foreshock sequences.

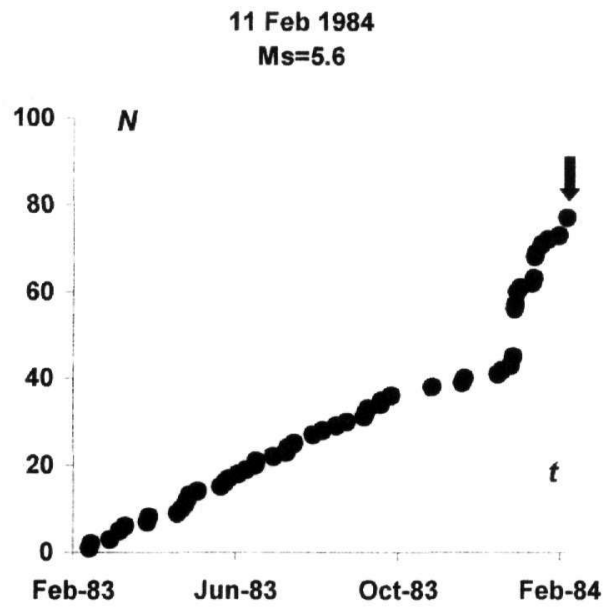

Figure 2. Example foreshock activity preceding the mainshock (black arrow) of 11 February 1984 in west Corinth Gulf. The foreshock sequence starts by the beginning of January 1984. $\mathrm{N}=$ cumulative number of earthquakes, $t=$ time.

\section{Jun 1995}

$\mathrm{Ms}=6.2$

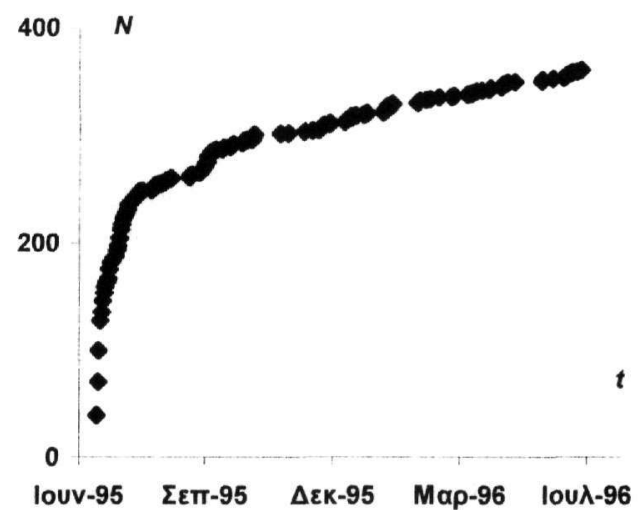

\section{THE DATA}

Seismicity data contained in the earthquake catalogue of the Institute of Geodynamics, National Observatory of Athens (http://www.gein.noa.gr) were examined for the time interval from 1980 to 2002 inclusive. The area under study was defined by the rectangle with coordinates $37.9^{0} \mathrm{~N}-38.5^{\circ} \mathrm{N}$ and $21.7^{\circ} \mathrm{E}-23.3^{\circ} \mathrm{E}$ (Fig. 1). Completeness analysis based on the magnitude-frequency relationship showed that the seismicity data are complete for local magnitude, $M_{L}$, equal to or larger than 2.8 , or for surface wave magnitude $M_{s} \geq 3.3$. From this catalogue we removed aftershock and foreshock sequences of ten strong $\left(M_{L} \geq 4.5\right)$ mainshocks. Aftershock and foreshock sequences were determined as sets of earthquakes, occurring within a distance of $1 / 3^{\circ}$ from the mainshock epicenter, and gradually decreases or increases in number following the Omori-law or the Mogi-law, respectively, both of them being expressed by equation 1 . The termination of an aftershock sequence or the onset of a foreshock sequence is identified at the point of time where the seismicity rate becomes about equal to, or starts to deviate from, the mean rate of background seismicity, respectively. Examples are illustrated in Figures 2 and 3. This procedure generated a new declustered catalogue which describes the background seismic activity. For reasons explained below we also 
calculated for the declustered catalogue the b-value of the magnitude-frequency relationship (Fig. 4), which was found equal to 0.92 .

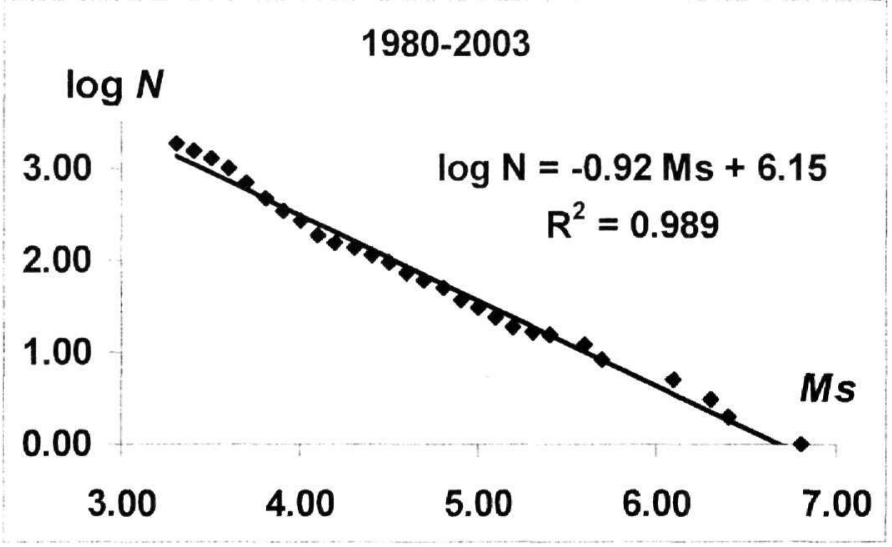

Figure 4. Magnitude-frequency relation for background seismicity of the Corinth Gulf.

\section{CRITERIA FOR THE IDENTIFICATION OF SWARMS}

An earthquake sequence could be defined as of swarm-type when its mean rate of activity exceeds significantly the mean rate of background activity and, at the same time, it does not contain a mainshock, that is an event significantly exceeding in magnitude all the rest events of the sequence. Because of the second criterion the b-value of swarms as a rule exceeds significantly that of the background seismicity.

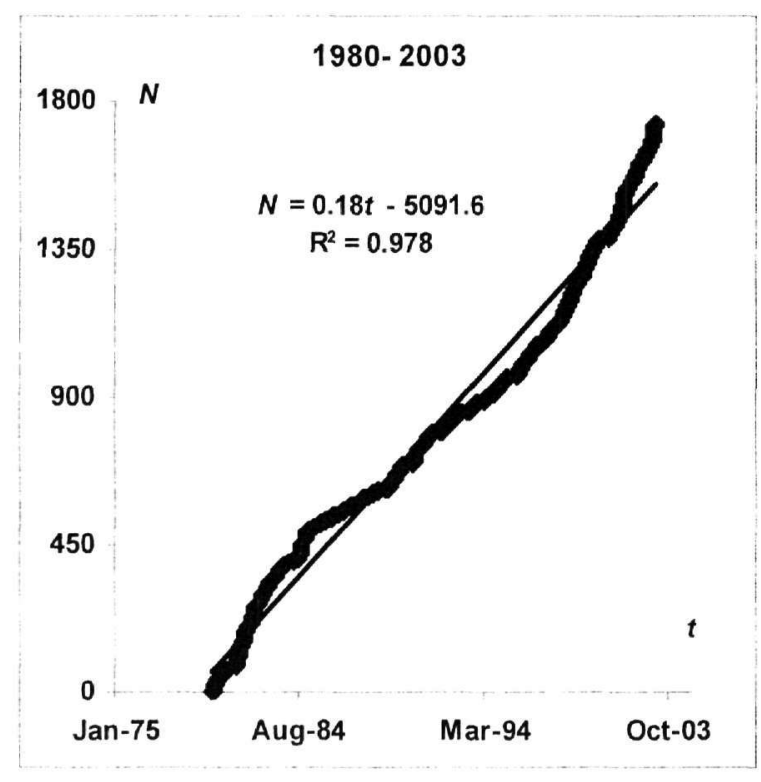

Figure 5 . Background seismicity rate ( $=0.18$ events/day) of the Corinth Gulf. $\mathrm{N}=$ cumulative number of earthquakes, $t=$ time. 
However, this criterion is frequently impossible to apply because of the relatively low number of earthquakes involved in each independent swarm. As an alternative we defined a swarm as a set of timely sequential earthquakes containing at least ten events and making a seismicity rate larger than the background rate so that the probability of its occurrence by chance within the particular time interval is less than $1 \times 10^{-3}$, which meets common standards used in statistical analysis. The calculation of the probability was based on the Poisson model (eq. 2), where $P(x)$ is the probability for the occurrence by chance of a number of $x$ events in a time interval of t days, where $\lambda=0.18$ events/day is the background seismicity rate (Fig. 5).

$$
P(x)=\frac{e^{-\lambda \cdot t}(\lambda \cdot t)^{x}}{x !}
$$

After the selection of a number of swarms on the basis of this definition we checked whether or not they satisfy the criterion of high b-value. By applying the above definition in the declustered catalogue, we were able to identify seventeen swarms (Table 1), nine of them including more than 40 earthquake events. The swarms with code numbers 2 and 3 as well as those with code numbers 14,15 and 16 are partly overlapping in time.

Table 1.Start and end dates of the swarms identified in the declustered catalogue. Key: $d=$ duration, $n=n u m b e r$ of events, $M s_{\min }=$ minimum magnitude involved, $M s_{\max }=$ maximum magnitude involved, $P(x)=$ probability for the number of events $n$ to appear by chance within time interval of $d$ days.

\begin{tabular}{cccccccccc}
\hline No & Start & End & $\begin{array}{c}\text { d } \\
\text { (days) }\end{array}$ & $\begin{array}{c}\text { n } \\
\text { (events) }\end{array}$ & $\begin{array}{c}\text { Rate } \\
\text { (events/day) }\end{array}$ & b-value & Ms min & Ms max & P(x) \\
\hline 1 & $29 / 02 / 80$ & $31 / 03 / 80$ & 30 & 27 & 0.90 & & 3.3 & 4.3 & $1.59^{*} 10^{-11}$ \\
2 & $02 / 07 / 81$ & $10 / 09 / 82$ & 435 & 167 & 0.38 & 1.22 & 3.3 & 4.8 & $\rightarrow 0$ \\
3 & $27 / 09 / 81$ & $10 / 09 / 82$ & 343 & 127 & 0.37 & 1.27 & 3.3 & 4.8 & $3.40^{\star} 10^{-14}$ \\
4 & $27 / 09 / 81$ & $26 / 12 / 82$ & 455 & 156 & 0.34 & 1.32 & 3.3 & 4.8 & $\rightarrow 0$ \\
5 & $23 / 03 / 82$ & $11 / 04 / 82$ & 19 & 27 & 1.42 & & 3.3 & 4.5 & $4.89^{*} 10^{-16}$ \\
6 & $05 / 08 / 84$ & $19 / 08 / 84$ & 14 & 21 & 1.50 & & 3.3 & 4.7 & $2.91^{*} 10^{-13}$ \\
7 & $09 / 11 / 84$ & $29 / 11 / 84$ & 20 & 22 & 1.10 & & 3.3 & 3.9 & $2.90^{*} 10^{-11}$ \\
8 & $07 / 05 / 89$ & $15 / 05 / 89$ & 8 & 14 & 1.75 & & 3.3 & 4.8 & $3.48^{*} 10^{-10}$ \\
9 & $15 / 07 / 90$ & $11 / 08 / 90$ & 27 & 23 & 0.85 & & 3.3 & 3.7 & $1.29^{*} 10^{-9}$ \\
10 & $13 / 09 / 98$ & $26 / 09 / 98$ & 13 & 22 & 1.69 & & 3.3 & 4.4 & $7.64^{*} 10^{-15}$ \\
11 & $13 / 09 / 98$ & $14 / 11 / 98$ & 62 & 42 & 0.68 & 1.54 & 3.3 & 4.4 & $5.44^{*} 10^{-13}$ \\
12 & $18 / 07 / 99$ & $31 / 07 / 99$ & 13 & 13 & 1.00 & & 3.3 & 4.1 & $7.86^{*} 10^{-7}$ \\
13 & $18 / 03 / 01$ & $12 / 06 / 01$ & 86 & 64 & 0.74 & 1.53 & 3.3 & 4.6 & $7.80^{*} 10^{-21}$ \\
14 & $16 / 09 / 02$ & $01 / 01 / 03$ & 107 & 71 & 0.66 & 1.81 & 3.3 & 4.5 & $2.89^{*} 10^{-20}$ \\
15 & $13 / 10 / 02$ & $01 / 01 / 03$ & 80 & 57 & 0.71 & 1.70 & 3.3 & 4.5 & $6.17^{*} 10^{-18}$ \\
16 & $19 / 11 / 02$ & $01 / 01 / 03$ & 43 & 43 & 1.00 & 1.60 & 3.3 & 4.5 & $5.80^{*} 10^{-19}$ \\
17 & $19 / 11 / 02$ & $05 / 02 / 03$ & 78 & 54 & 0.69 & 1.65 & 3.3 & 4.5 & $1.40^{*} 10^{-16}$ \\
\hline
\end{tabular}

\section{CRITERIA FOR THE DISCRIMINATION BETWEEN FORESHOCKS AND SWARMS}

\subsection{The b-value}

The difference in the b-value is one of the criteria that can be used to discriminate between foreshock sequences and swarms. The reliability of the b-value estimation depends on several factors like the rumber and the magnitude range of events in the data set. As for the number of events the larger this number the better the result. As for the magnitude range, it has been shown (e.g. Papazachos, 1974) that it should exceed 1.5. We calculated the b-value for only the nine clusters that contain more than forty earthquake events each, because for the others the low number of events involved does not allow for a reliable estimation. The magnitude range in the nine data sets examined is between 1.1 to 1.5 which may signifies some unreliability of the results. However, the 
systematic increased value of the parameter $b$ found for all the data sets is an indication the result is in general correct. Obviously, in case of an actually evolving earthquake sequence the estimation of the $b$-value can be done only if a sufficient number of events has been recorded. This means that this discrimination criterion is not possible to apply from the very beginning of the activity. The $b$-values of the nine swarms were found to be systematically high with respect to the background bvalue of 0.92 . The differences between the $b$-value of each one swarm and the background $b$-value are significant at the $99 \%$ level.

\subsection{Time distribution and numbers of events}

An additional criterion for discrimination could be based on the number of events and the duration of the activity (Figs. 6, 7).. By the beginning of the activity the number of events is only sharply higher in swarms than in foreshock sequences. However, for time periods longer than twenty days the number of events becomes systematically higher for the same time after the beginning of the activity. In fact, twenty days and sixty days after the beginning the number of events is nearly 1.5 and 2 times higher in swarms than in foreshocks, respectively. The total duration of foreshock sequences do not exceed four months. However, the total duration of a swarm may reach up to fifteen months.

\subsection{Space distribution of events}

From the study of Corinth Gulf foreshock sequences it resulted that the epicenters of the events of a particular sequence are concentrated in regions of radius of no more than about $30 \mathrm{~km}$ or $1 / 3^{0}$ around the mainshock' s epicenter (Papadopoulos et al., 2000). However, the epicentral distribution of the swarms studied here shows that as a rule the events contained in a particular swarm are extended over the entire Corinth Gulf. This property makes an additional discrimination criterion.

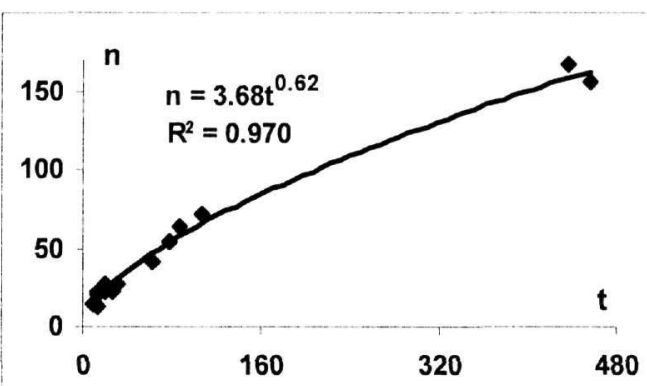

Figure 6. Number, $n$, of events contained in Corinth Gulf swarms against the swarm total duration, $\mathrm{t}$ (in days).

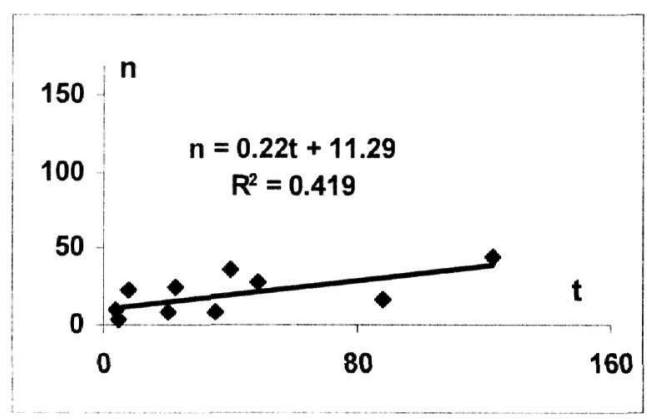

Figure 7. Number, $n$, of events contained in Corinth Gulf foreshock sequences against the sequence total duration, $t$ (in days) (data from Papadopoulos et al. 2000.)

\section{CONCLUSIONS}

The different space-time-size distributions of swarms and foreshock sequences in the Corinth Gulf make a good basis for the development of an algorithm towards the real-time discrimination between the two types of seismic activity. In particular, the b-value of the magnitude-frequency relation is significantly high in swarms $(b, 1.2)$ with respect to that in background seismicity $(b \sim 1)$ which is higher than the b-value $(<1)$ in foreshocks. In addition, the duration of the swarms usually exceeds that of the foreshocks while the number of events contained in a swarm, as a rule is larger than that of foreshocks for the same point of time from the beginning of the activity. In addition, the epicenters of the events contained in a particular swarm as a rule are extended over the entire Corinth Gulf, while the foreshock epicenters are concentrated at a distance of no more than about $30 \mathrm{~km}$ around the mainshock's epicenter. These criteria of discrimination provide possibilities for a 
probabilistic decision making as regards the real-time identification of the onset of foreshock sequences in the Corinth Gulf.

\section{REFERENCES}

Agnew, D.C., and Jones, L.M., 1991. Prediction probabilities from foreshocks, J. Geophys. Res., 96, 11,95911,971 .

Chen, Y., Liu, J., and Ge, H., 1999. Pattern characteristics of Foreshock Sequences, Pure appl. Geophys., 155, 395-408.

Jones, L.M., 1984. Foreshocks (1966-1980) in the San Andreas system,California, Bull. Seismol. Soc. Amer., $74,1361-1380$.

Jones, L.M., 1985. Foreshocks and time-dependent earthquake hazard assessment in Southern California, Bull. Seismol. Soc. Amer., 75, 1669-1679.

Jones, L.M., and Molnar, P., 1979. Some characteristics of foreshocks and their possible relationship to earthquake prediction and premonitory slip on faults, J. Geophys. Res., 84, 3596-3608.

Ishida, M., and Kanamori, H., 1978. The foreshock activity of the 1971 San Fernando earthquake, California, Bull. Seismol. Soc. Amer., 68, 1265-1279.

Kagan, Y., and Knopoff, L., 1978. Statistical study of the occurrence of shallow earthquakes, Geophys. J. $R$. astr. Soc., $55,67-86$

Michael, A.J., and Jones, L.M., 1998. Seismicity alert probabilities at Parkfield California, revisited, Bull. Seismol. Soc. Amer., 88, 117-130.

Molchan, G.M., and Dmitrieva, O.E., 1990. Dynamics of the magnitude-frequency relation for foreshocks, Phys. Earth Planet. Int., 61, 99-112.

Ogata, Y., Utsu, T., and Katsura, K., 1996. Statistical discrimination of foreshocks from other earthquake clusters, Geophys. J. Int., 127, 17-30.

Papadopoulos, G.A., Makropoulos, K.C., and Dedousis, V., 1991. Preqursory variations of the foreshocks fractal dimension in time, International Conference on Earthquake Prediction : state - of - the - art, France, Council of Europe, 92-97.

Papadopoulos, G.A., Drakatos, G., and Plessa, A., 2000. Foreshock activity as a precursor of strong earthquakes in Corinthos Gulf, Central Greece, Phys. Chem. Earth, 25, 239-245.

Papazachos, B.C., 1973. The time distribution of the reservoir-associated foreshocks and its importance to the prediction of the principal shock, Bull. Seismol. Soc. Amer., 63, 1973-1978.

Papazachos, B.C., 1974. Dependence of the seismic parameter b on the magnitude range, Pure appl. Geophys., 112, $1059-1065$.

Papazachos, B.C., 1975. Foreshocks and earthquake prediction, Tectonophysics, 28, 213-226.

Reasenberg, P.A., 1999. Foreshock occurrence before large earthquake, J. Geophys. Res., 104, 4755-4768.

Suyehiro, S., and Sekiya, H., 1972. Foreshocks and earthquake prediction, Tectonophysics, 14, 219-225.

Wong, K.C., and Wyss, M.,1985. Clustering of Foreshocks and Preshocks in the Circum-Aegean region, Earthq. Predict. Res., 3, 121-140. 